\title{
Evaluation of Piezoresistivity Properties of Sputtered ZnO Thin Films
}

\author{
Guilherme Wellington Alves Cardoso ${ }^{\text {a*, Gabriela Leal }}{ }^{\mathrm{a}}$, Argemiro Soares da Silva Sobrinho ${ }^{\mathrm{a}}$ \\ Mariana Amorim Fraga ${ }^{\mathrm{b}}$, Marcos Massi ${ }^{\mathrm{a}, \mathrm{c}}$ \\ anstituto Tecnológico de Aeronáutica - ITA, São José dos Campos, SP, Brasil \\ ${ }^{\mathrm{b}}$ Faculdade de Tecnologia de São Paulo - FATEC-SP, São Paulo, SP, Brasil \\ ${ }^{\mathrm{c}}$ Universidade Federal de São Paulo - UNIFESP, São José dos Campos, SP, Brasil
}

Received: June 6, 2013; Revised: April 22, 2014

\begin{abstract}
Zinc oxide $(\mathrm{ZnO})$ thin films were deposited by RF reactive magnetron sputtering on silicon (100) substrates under different experimental conditions. $\mathrm{ZnO}$ films were studied before and after annealing treatment at $600{ }^{\circ} \mathrm{C}$. The crystallinity, electrical resistivity, stoichiometry, thickness, and elastic modulus of the films were investigated. $\mathrm{ZnO}$ piezoresistors were produced using microelectronics processes, such as photolithography, lift-off, and reactive ion etching (RIE). Cantilever method was used to determine the gauge factor, and measurements of Temperature Coefficient of Resistance (TCR) were performed on a hotplate. The optimization of the deposition conditions produced $\mathrm{ZnO}$ thin films with controlled stoichiometry ( $\mathrm{ZnO})$, crystalline microstructure (phase wurzite, 002), high elastic modulus $(156 \mathrm{GPa})$, and low electrical resistivity $(0.072 \mathrm{ohm} . \mathrm{cm})$, which are good properties for application as piezoresistive pressure microsensor. In addition, the $\mathrm{ZnO}$ piezoresistors had a GF of 2.6 on the deformation in the plane (100) and TCR of $-1610 \mathrm{ppm} / \mathrm{K}$ up to $250{ }^{\circ} \mathrm{C}$.
\end{abstract}

Keywords: $\mathrm{ZnO}$, thin film, magnetron sputtering, piezoresistivity

\section{Introduction}

Zinc oxide $(\mathrm{ZnO})$ thin films have been used in the fabrication of electronics devices such as diodes ${ }^{1}$, thin films transistors (TFTs) ${ }^{2}$, and Micro-Electro-Mechanical System (MEMS) such as gas sensors ${ }^{3}$. $\mathrm{ZnO}$ is a wide band gap $(3.37 \mathrm{eV})$ semiconductor material with thermal and chemical stabilities. The combination of these properties with the outstanding piezoelectric characteristics make this material a potential candidate to replace silicon in MEMS sensors employed in hostile environments, i.e. at high temperatures.

The literature mostly presents works related to piezoresistive properties of high band gap materials such as silicon carbide ( $\mathrm{SiC}$ ) and diamond. On the other hand, few studies report the piezoresistive characteristics of $\mathrm{ZnO}$. This may be attributed to the following reasons: (a) the piezoelectric properties of $\mathrm{ZnO}$ are well documented in the literature ${ }^{4-6}$; (b) compared to $\mathrm{SiC}^{7}$ and diamond, $\mathrm{ZnO}$ exhibits lower electromechanical properties.

Despite the lower electromechanical characteristics when compared to other semiconductor materials, $\mathrm{ZnO}$ may have advantages because its crystallographic structure is well defined ${ }^{8}$. The ordered crystallographic configuration of $\mathrm{ZnO}$ is related to the substrate type and deposition parameters employed during its formation. On the other hand, SiC has more than 200 polytypes with different physical properties ${ }^{9}$, and the highly ordered atomic structure of diamond inhibits doping processes necessary to reduce its resistivity.

The ability to change electrical resistivity when submitted to mechanical stress is known as the piezoresistive

*e-mail: guilherme_wa@hotmail.com effect, which depends on the doping concentration, crystallographic orientation, and temperature ${ }^{10}$. The piezoresistive effect can be determined by a Gauge Factor (GF), which shows the variation of electrical resistance and strain according to Equation 1.

$G F=\frac{\Delta R}{R} \cdot \frac{1}{\varepsilon}$

Where $\Delta \mathrm{R}$ is the variation of electrical resistance and $\varepsilon$ is the strain.

Monocrystalline P type silicon has higher GF (around 140) at room temperature. However, at temperatures higher than $125^{\circ} \mathrm{C}$, this factor is significantly reduced. SiC piezoresistors can exhibit GF in the range of 8 to 50 and thermal stability up to $500{ }^{\circ} \mathrm{C}$ according to their crystalline structure $^{11}$. For these reasons, $\mathrm{ZnO}$ is considered as an alternative material in piezoresistive devices due to its thermal stability, which is similar to $\mathrm{SiC}$, ease of synthesis, and well controlled deposition parameters.

Cold plasma assisted techniques have been extensively used to grown these films, because at low temperatures, damage to the previously processed devices are avoided. Among these techniques, Physical Vapor Deposition (PVD) is the most used ${ }^{12}$.

\section{Experimental}

\subsection{Samples}

RF magnetron sputtering technique was used to deposit $\mathrm{ZnO}$ thin films on $\mathrm{Si}$ (100) p-type substrates with resistivity 
about 1-10 $\Omega . \mathrm{cm}$. The silicon substrates were previously cleaned with a solution of $\mathrm{H}_{2} \mathrm{SO}_{4}-\mathrm{H}_{2} \mathrm{O}_{2}$ (4:1) and then with $\mathrm{H}_{2} \mathrm{O}-\mathrm{HF}(20: 1)$. In order to remove the target oxide layer, $10 \mathrm{~min}$ of a pre-sputtering in argon atmosphere was done. Zinc oxide target $(99.99 \%$ ) located at $75 \mathrm{~mm}$ from the substrate was used as cathode target. The deposition time of $60 \mathrm{~min}$ and the total gas flow of $20 \mathrm{sccm}(19 \mathrm{sccm}$ $\mathrm{Ar}$ and $1 \mathrm{sccm} \mathrm{O}$ ) were kept constant. Table 1 summarizes the varied parameters used in the $\mathrm{ZnO}$ deposition processes.

Each sample was divided into two similar pieces. One of them was annealed at $600{ }^{\circ} \mathrm{C}$ with heating rate of $20^{\circ} \mathrm{C} / \mathrm{min}$ at $8.0 .10^{-3}$ Torr for $60 \mathrm{~min}$. The samples were kept inside the oven until completely cooled.

\subsection{Analysis}

The thin-film resistivity and crystallinity were characterized using the four point probe technique (Jandel RM3 with 4 points probes) and X-ray diffraction technique (Shimadzu, model XRD-6000, Cu-K $\alpha, \lambda=1.54 \AA$ ), respectively. The film thicknesses were determined using a profilometer (Tencor Instruments Alpha-Step 500). The film compositions were investigated by Rutherford Backscattering Spectroscopy (RBS), and the spectra analyzed using the RUMP simulation code.

The elastic modulus of the $\mathrm{ZnO}$ films was obtained by nanoindentation (Hysitron Triboindenter 900). Piezoresistors were fabricated by lithographic process (Figure 1) and characterized by the cantilever method (Figure 2). This process consists of a cantilever with a fixed extremity, where the piezoresistor is placed, and a free extremity, where a calibrated mass is placed, which causes mechanical stress in the piezoresistor. The piezoresistor resistance was measured without mechanical stress $\left(R_{0}\right)$ and with mechanical stress $\left(R_{f}\right)$, caused by a mass placed in the free

Table 1. Deposition parameters.

\begin{tabular}{ccc}
\hline Sample & Discharge Power $(\mathbf{W})$ & Working pressure (mTorr) \\
\hline 1 & 100 & 5 \\
2 & 150 & 5 \\
3 & 200 & 5 \\
4 & 100 & 15 \\
5 & 150 & 15 \\
6 & 200 & 15 \\
\hline
\end{tabular}

cantilever extremity $\left(R_{f}\right)$. Equation 2 was used to determine the resistance variation $(\Delta R / R)$.

$$
\frac{\Delta R}{R}=\frac{R f-R_{0}}{R_{0}}
$$

\section{Results and Discussions}

Figure 3 shows the deposition rates of the films as a function of applied power and work pressure. The increase of applied power provides an increase in deposition rate of the films as expected. An increase in deposition rate decreased the work pressure ${ }^{13}$. This phenomenon is related to the increase of the sputtered particles arriving in the substrate at lower pressures.

Figure 4 shows the X-ray diffraction spectra of $\mathrm{ZnO}$ thin films. Samples 4, 5, and 6, (obtained at higher working pressures) have peaks at $34.4^{\circ}$ (002 - wurzite phase), which are smaller and more extended than those obtained for samples 1,2, and 3, indicating a more disorganized structure, and therefore, less crystalline. At low pressure, the particles produced a substrate with higher values of energy and can form zinc silicate $\left(\mathrm{Zn}_{2} \mathrm{SiO}_{4}\right)$ film in the interface, with peak at $25.3^{\circ}(220)^{14}$.

In addition to the influence of work pressure on the crystallinity of the film, the diffraction patterns also show the influence of the applied power on the film characteristics. As previously mentioned, the sample deposited at higher pressure and lower power (sample 4) has low intensity peaks, and inversely, samples deposited at $5 \mathrm{mTorr}$ and higher power have higher crystallinity. The peak centered at $33.2^{\circ}$ refers to silicon substrate.

Four-point probe measurements were performed on all samples, and only samples 2 and 3 had low resistivity, 0.072 and $0.351 \Omega . c m$, respectively. The other samples showed resistivity out of the 4-point probe scale $\left(0.5 .10^{9} \Omega / \square\right)$.

Based on these results, samples 2 and 3 had lower resistivity and good crystallinity and were selected to analyze their piezoresistive behavior. Therefore, these two samples were annealed at $600{ }^{\circ} \mathrm{C}$, and the X-ray diffraction patterns are performed (Figure 5). After the annealing process, the samples showed well defined peaks centered at $34.6^{\circ}$. The films are also free of stress, because they possess the central peak equal to the XRD pattern for the $\mathrm{ZnO}$ in wurzite phase to the plane 002. Furthermore, the amorphous band (at approximately 30 degrees) disappeared after annealing and the peak of $25.3^{\circ}\left(\mathrm{Zn}_{2} \mathrm{SiO}_{4}\right)$ decreased,

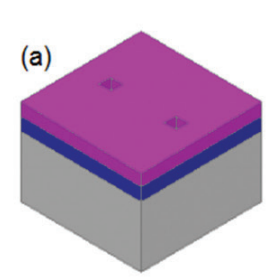

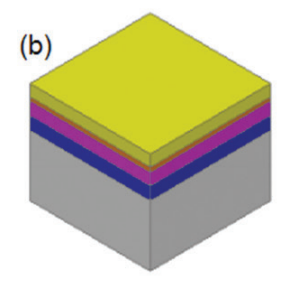

Si

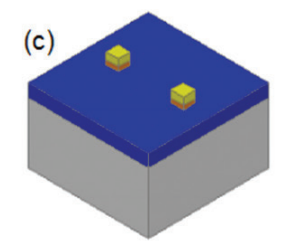

$\mathrm{ZnO}$
Ti $\mathrm{Tu}$
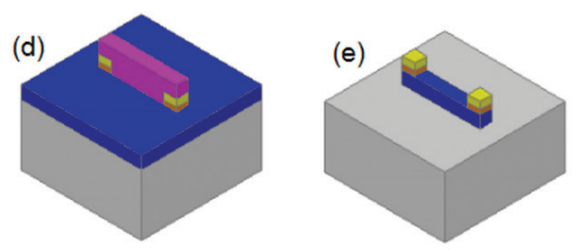

Photoresist

Figure 1. Schematic drawing of the manufacturing process of the resistors, in a) photoresist deposition on $\mathrm{ZnO}$ thin film and contact lithography; b) Ti and Au deposition on photoresist to contacts; c) lift-off to contact formation; d) photoresist deposition and resistor lithography; e) RIE to resistor formation. 


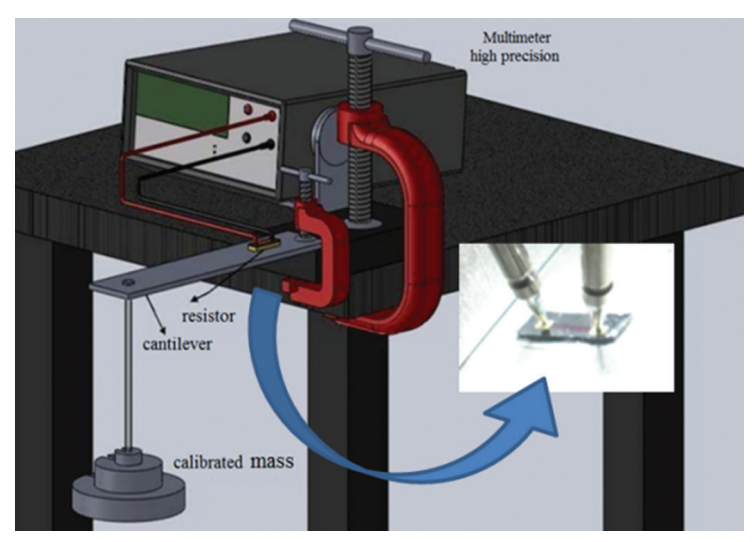

Figure 2. Schematic illustration of the experimental set-up used to characterize the piezoresistors.

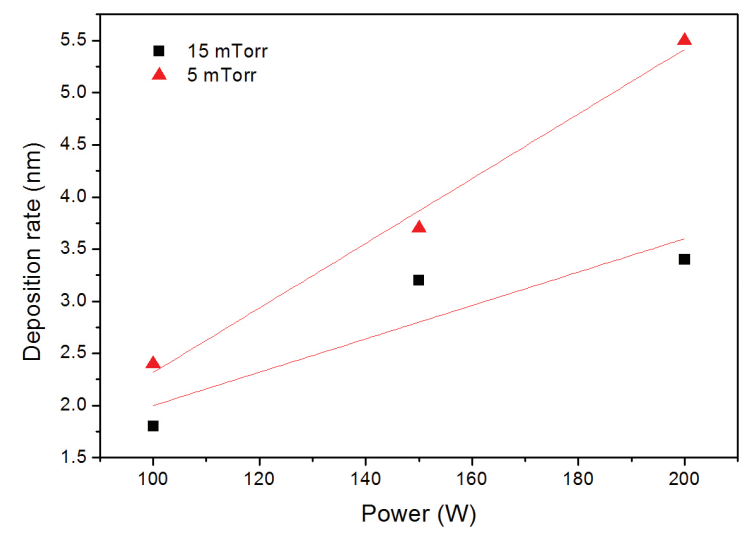

Figure 3. Deposition rate of the $\mathrm{ZnO}$ thin films.

which was a further indication that the material had higher crystallinity in wurzite phase.

RBS analysis showed the stoichiometric relation of the $\mathrm{Zn}$ and $\mathrm{O}$ atoms, independent of the work pressure or power applied. The contaminant presence is insignificant. Figure 6 shows the obtained and simulated spectrum of the sample 3R.

The resistivity of the films before and after annealing process is presented in Table 2 . The resistivity of the nonannealed samples is slightly lower than the annealed one.

The resistivity of a material is linked to the organization of its crystal lattice, and as illustrated by X-ray diffraction patterns, the films had higher crystallinity after thermal annealing, which directly reflects the values of resistivity ${ }^{15}$. However, if any contaminant contributes to doping, the resistance can vary to higher or lower values ${ }^{16}$.

Nanoindentation results of samples 2 and 3 before and after annealing are presented in Figure 7. The annealed samples showed higher elastic modulus than the nonannealed ones. Sample 2R, for example, had an elastic modulus of $156 \mathrm{GPa}$, which is in accordance with the literature. Annealed films with higher modulus of elasticity values are better for the fabrication of piezoresistive sensors. Therefore, samples $2 \mathrm{R}$ and $3 \mathrm{R}$ were selected to produce piezoresistors via photolithographic process.

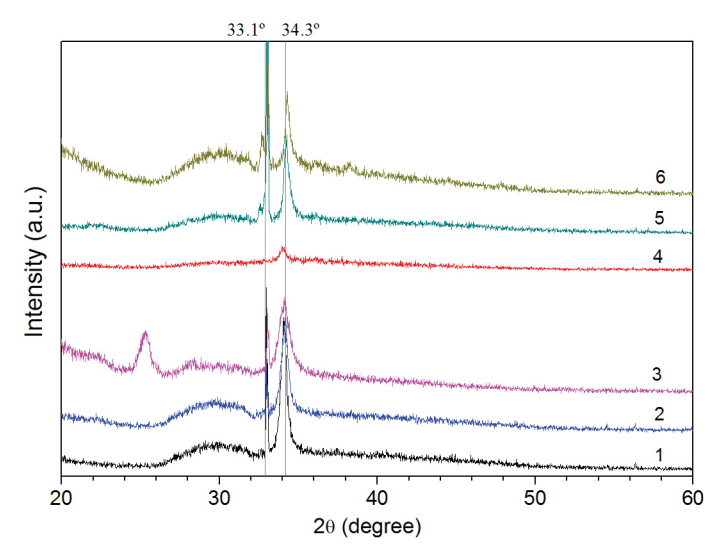

Figure 4. X-ray diffraction of the deposited films.

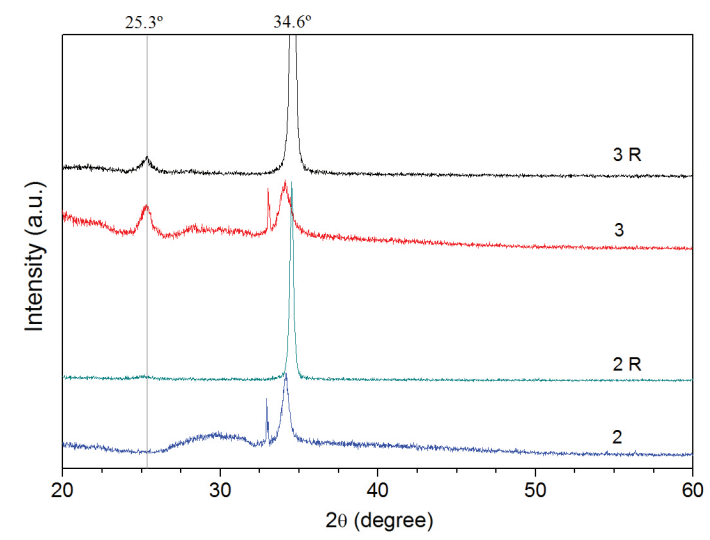

Figure 5. X-ray diffraction of samples before (2 and 3) and after (2R and $3 R$ ) annealing.

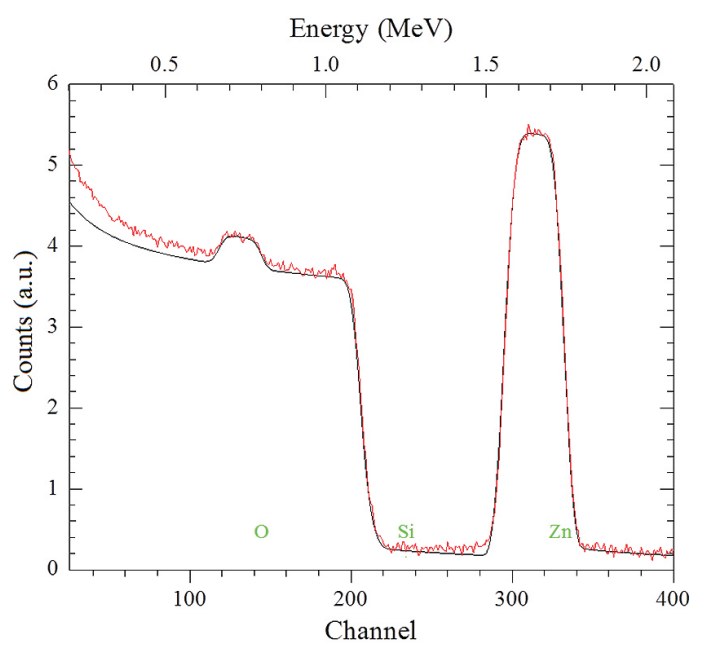

Figure 6. Real and simulated RBS spectrum of sample 2R.

Table 2. Resistivity of the films before and after the annealing.

\begin{tabular}{cc}
\hline Samples & Resistivity $(\Omega . c m)$ \\
\hline 2 & 0.072 \\
$2 \mathrm{R}$ & 0.074 \\
3 & 0.351 \\
$3 \mathrm{R}$ & 1.855 \\
\hline
\end{tabular}




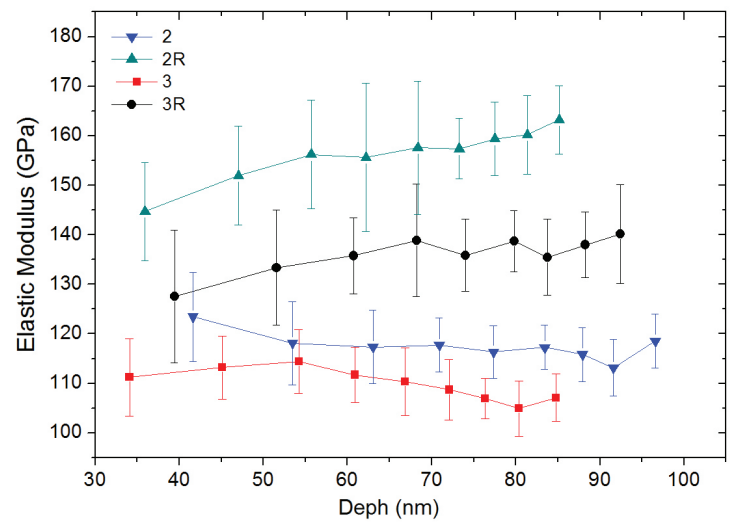

Figure 7. Elastic modulus of $\mathrm{ZnO}$ films.

The variation of the resistance as function of the mass applied is shown in Figure 8. Sample 2R had higher elastic modulus, lower resistivity, and a smaller thickness, and it also achieved greater sensitivity to deformation. Low gauge factor of approximately $2.6 \pm 0.2$ for sample $2 \mathrm{R}$ and $1.00 \pm 0.05$ for $3 R$ was found.

The resistors $2 \mathrm{R}$ and $3 \mathrm{R}$ were characterized according to temperature coefficient of resistance (TCR), as shown in Figure 9. Sample $2 \mathrm{R}$ showed a small variation of resistance compared to sample 3R; even with less thickness, sample $2 \mathrm{R}$ is more thermally stable.

The $\mathrm{ZnO}$ films had an almost constant TCR up to $525 \mathrm{~K}$. A huge variation occurred above this temperature, suggesting that the morphological structure can have lattice parameter distortion, which can generate resistance variation and affect the use of this material as a pressure sensor above this temperature.

\section{Conclusion}

From the results obtained in this work, it is possible to conclude that the annealed samples 2 and 3 showed the best piezoresistivity characteristics due to their high elastic modulus and low resistivity. Both films had thermal stability up to $525 \mathrm{~K}$, and sample $2 \mathrm{R}$ had high sensitivity to deformation. Future works will be developed using $\mathrm{ZnO}$

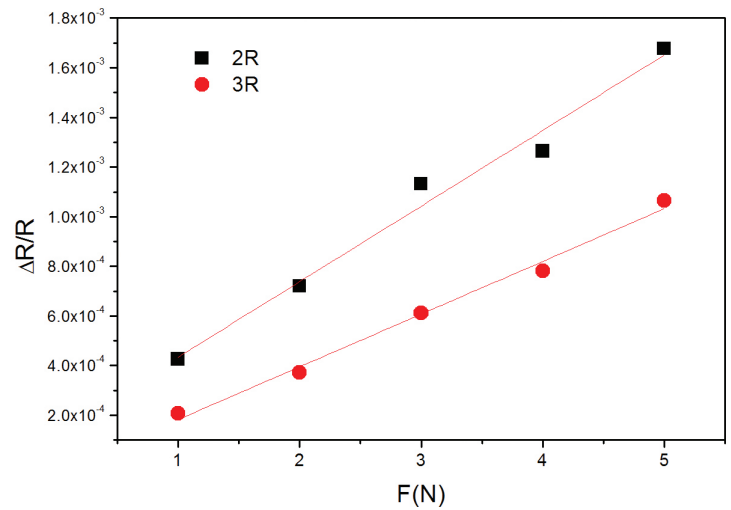

Figure 8. Relative change in resistance $(\Delta R / R)$ of the resistors as a function of the applied load on cantilever at room temperature.

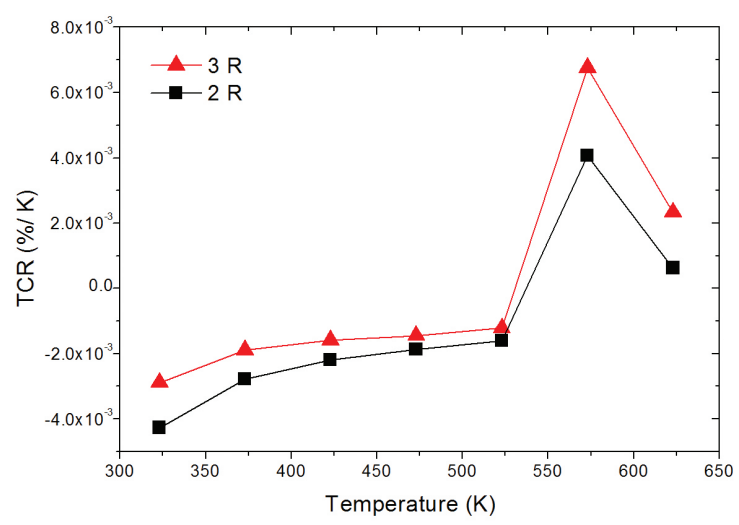

Figure 9. TCR of $\mathrm{ZnO}$ films.

doped with titanium (Ti), aluminum (Al), and molybdenum (Mo) to modify its net parameters and thus reduce the film resistivity in order to increase the piezoresistivity capacity.

\section{Acknowledgments}

We are thankful to LAS-INPE, LAMFI-IF-USP, LNNano-LNLS, and IP\&D-UNIVAP laboratories for the use of characterization equipment and CNPq, CAPES, and FAPESP for the financial support.

\section{References}

1. Lee SY, Shim ES, Kang HS, Pang SS and Kang JS. Fabrication of $\mathrm{ZnO}$ thin film diode using laser annealing. Thin Solid Films. 2005; 473(1):31-34. http://dx.doi.org/10.1016/j. tsf.2004.06.194

2. Lee K, Choi JM, Hwang DK, Oh MS, Kim JK, Jung Y et al. Top-gate $\mathrm{ZnO}$ thin-film transistors with a polymer dielectric designed for ultraviolet optical gating. Sensors and Actuators A: Physical. 2008; 144(1):69-73. http://dx.doi.org/10.1016/j. sna.2008.01.012

3. Al-Hardan NH, Abdullah MJ and Aziz AA. Sensing mechanism of hydrogen gas sensor based on RF-sputtered $\mathrm{ZnO}$ thin films.

International Journal of Hydrogen Energy. 2010; 35(9):44284434. http://dx.doi.org/10.1016/j.ijhydene.2010.02.006

4. Mitsuyu T, Ono S and Wasa K. Structures and SAW properties of rf-sputtered single-crystal films of $\mathrm{ZnO}$ on sapphire. Journal of Applied Physics. 1980; 51(5):2464-2470. http://dx.doi. org/10.1063/1.328019

5. Tang IT, Wang YC, Hwang WC, Hwang CC, Wu NC, Houng $\mathrm{MP}$ et al. Investigation of piezoelectric $\mathrm{ZnO}$ film deposited on diamond like carbon coated onto Si substrate under different sputtering conditions. Journal of Crystal Growth. 2003; 252(13):190-198. http://dx.doi.org/10.1016/S0022-0248(02)02496-X

6. Kang SJ and Joung YH. Influence of substrate temperature on the optical and piezoelectric properties of $\mathrm{ZnO}$ thin 
films deposited by rf magnetron sputtering. Applied Surface Science. 2007; 253(17):7330-7335. http://dx.doi.org/10.1016/j. apsusc.2007.03.020

7. Fraga MA, Furlan H, Massi M, Oliveira IC and Koberstein LL. Fabrication and characterization of a View the MathML source piezoresistive pressure sensor. Procedia Engineering. 2010; 5:609-6012. http://dx.doi.org/10.1016/j. proeng.2010.09.183

8. Sundaram KB and Khan A. Characterization and optimization of zinc oxide films by r.f. magnetron sputtering. Thin Solid Films. 1997; 295(1-2):87-91. http://dx.doi.org/10.1016/S00406090(96)09274-7

9. Robert JL, Contreras S, Camassel J, Pernot J, Neyret E, Cioccio L et al. 4H-SiC: a material for high temperature Hall sensor. Sensors and Actuators A. 2002; 97-98:27-32. http://dx.doi. org/10.1016/S0924-4247(01)00812-3

10. Strass J, Eickhoff M and Kroetz G. The influence of crystal quality on the piezoresistive effect of $\beta$-SiC between RT and $450^{\circ} \mathrm{C}$ measured by using microstructures. In: International Solid State Sensors and Actuators Conference (Transducers '97); 1997; Chicago. Volume 2. http://dx.doi.org/10.1109/ SENSOR.1997.635735
11. Cocuzza M. Development of Silicon Carbide-Based MicroEletromechanical Systems. [Thesis]. Trento: Universitá di Trento; 2006.

12. Madou MJ. Fundamentals of microfabrication: the science of miniaturization. Boca Raton: CRC Press; 2002. p. 144-152.

13. Gao $\mathrm{W}$ and $\mathrm{Li} \mathrm{Z}$. ZnO thin films produced by magnetron sputtering. Ceramics International. 2004; 30(7):1155-1159. http://dx.doi.org/10.1016/j.ceramint.2003.12.197

14. Wang WC, Tian YT, Li K, Lu EY, Gong DS and Li XJ. Capacitive humidity-sensing properties of $\mathrm{Zn} 2 \mathrm{SiO} 4$ film grown on silicon nanoporous pillar array. Applied Surface Science. 2013; 273:372-376. http://dx.doi.org/10.1016/j. apsusc.2013.02.045

15. Kim KS, Kim HW and Kim NH. Physica B: Condensed Matter. 2003; 334(3-4):343-346. http://dx.doi.org/10.1016/ S0921-4526(03)00096-6

16. Wenas WW, Yamada A, Takahashi K, Yoshino M and Konagai M. Electrical and optical properties of boron-doped $\mathrm{ZnO}$ thin films for solar cells grown by metalorganic chemical vapor deposition. Journal of Applied Physics. 1991; 70:7119-7123. http://dx.doi.org/10.1063/1.349794 